http://dx.doi.org/10.1590/0370-44672014700205

\author{
Nádia Cazarim da Silva Forti \\ Professora Pesquisadora \\ Pontifícia Universidade Católica de Campinas - PUC \\ Centro de Ciências Exatas, \\ Ambientais e de Tecnologia - CEATEC \\ Campinas - São Paulo - Brasil \\ nadia.cazarim@puc-campinas.edu.br
}

\section{João Alberto Venegas Requena}

Professor Associado

Universidade Estadual de Campinas - UNICAMP

Faculdade de Engenharia Civil,

Arquitetura e Urbanismo

Campinas - São Paulo - Brasil

requena@fec.unicamp.br

\section{Tiago Luís Duarte Forti}

Engenheiro Civil

Simworx Engenharia, Pesquisa e Desenvolvimento

Campinas - São Paulo - Brasil

forti@simworx.com.br

\section{Introduction}

Tubular components are commonly employed in structures when their use permits lighter construction or a reduced number of pieces. In infrastructure applications, this typically occurs in long span structures (30-50 $\mathrm{m}$ or more) such as stadium roofs, airports, convention centers,

\title{
Numerical methodology for analyses of tubular KK multiplanar steel joints
}

\section{Abstract}

Herein is presented a numerical methodology for a static resistance analysis of symmetrically loaded multiplanar KK joints in circular hollow steel sections. This methodology addresses factors related to the simulation of $\mathrm{KK}$ joints such as the material properties, the boundary conditions, mesh generation and refinement, incremental load steps and failure criteria. An objective criterion is proposed to identify the two failure modes most often occurring in KK joints. Failure mode 1 is observed when two neighboring diagonal braces loaded in the same sense act as one brace penetrating the chord together. In the failure mode 2, excessive deformation is observed in the chord region between two neighboring braces, folding the chord wall. However, in some cases the failure mode is not easily identified or both failure types are present. The proposed criterion objectively identifies the failure mode. In order to compute the joint resistance, an important failure criterion often adopted in literature for uniplanar $\mathrm{K}$ joints is the one known as Lu's deformation. In this paper, a strategy is proposed, which is an extension of Lu's criterion for multiplanar KK joints.

Keywords: steel structures, hollow steel sections, multiplanar joints, numerical simulation.

bridges, telecommunication towers, and offshore equipment. For these structures, the multiplanar configuration (Figure 1) with a circular hollow section is widely employed. The design of multiplanar hollow KK joints traditionally follows the guidelines for uniplanar joints, which were developed based

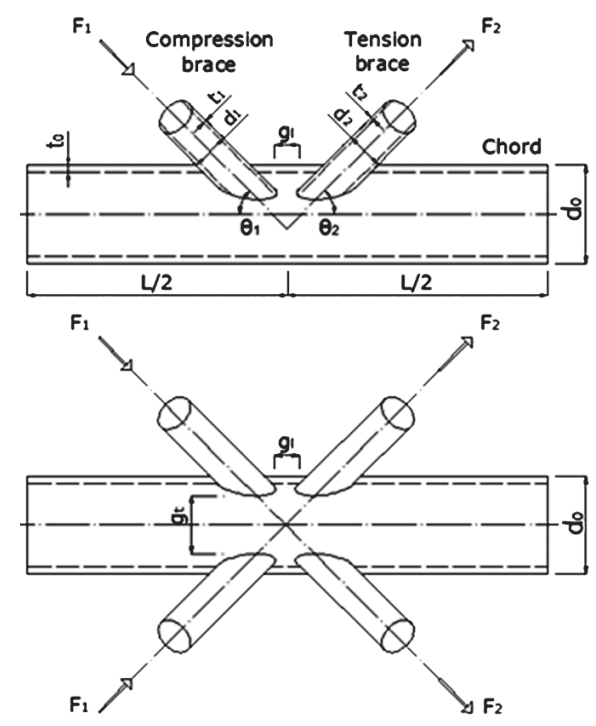

on laboratory test results and most recently revised based on Finite Element simulations (van der Vegte and Wardenier 2014). The standard practice is to treat every plane separately and to multiply the resistance by a unique correlation coefficient that is independent of the joint geometry.
Figure 1

Geometric parameters of multiplanar KK joint. 
The study of multiplanar interaction effects on the static resistance of tubular joints dates back to 1984, when Makino et al. (1984) described a series of tests on multiplanar KK joints in Japan. As the interest in multiplanar joints grew, several studies were undertaken worldwide. Important works on $\mathrm{KK}$ joints include Mouty and Rondal (1990), Makino et al. (1993), and Paul et al. (1992). Makino et al. (1984) tested $20 \mathrm{KK}$ joints and identified two failure modes occurring when the joint was symmetrically loaded. Joints with

The geometric parameters of multiplanar KK joints presented in Figure 1 usually have some limits for application. When designed according to the Eurocode 3 (2005), for instance, the joint has to respect the following:

- $30^{\circ} \leq \theta_{i} \leq 60^{\circ}$ (angle in-plane between brace and chord);

\section{Numerical simulation}

This paper presents a numerical methodology for the static resistance analysis of symmetrically loaded multiplanar KK joints in circular hollow steel sections. This numerical model was applied to a parametric study of KK joints,

\subsection{Definitions}

A multilinear isotropic hardening (MISO) stress-strain curve was used. The von Mises yield criterion was adopted. The simulation parameters affecting the static resistance, such as the boundary conditions, the chord and brace lengths, a small transversal gap (gt, Figure 1) failed in mode 1 (Figure 2a), in which the two diagonal braces act in unison without wall deformation in the transversal gap region. Other joints failed in mode 2 (Figure 2b), in which excessive deformation occurs near the transversal gap. In 1995, Lee and Wilmshurst (1995) presented a finite element analysis of KK joints. This was followed by a parametric study of KK joints (Lee and Wilmshurst 1996) and a study of KK joints under asymmetric loading (Lee and Wilmshurst 1997). Methodologies for
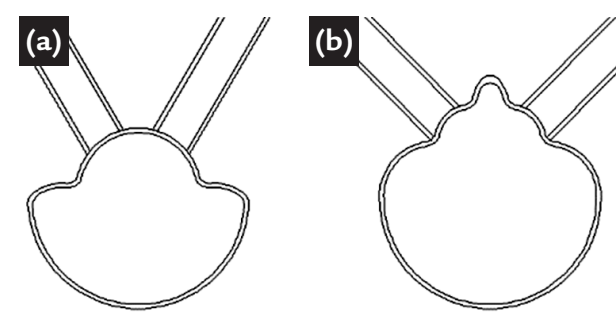

- $\gamma=\frac{d_{i}}{2 t_{i}} \leq 25$ and $0.2<\frac{d_{i}}{d_{0}} \leq 1.0$, where $d_{i}$ is the brace diameter, $t_{i}$ is its thickness and $d_{0}$ is the chord diameter;

- $10 \leq 2 \gamma=\frac{d_{0}}{t_{0}} \leq 50$,

where $d_{0}$ is the chord diam-

comparing their joint resistance to those of their equivalent $\mathrm{K}$ joints. (Forti et al. 2015). The joints are calculated using the commercial finite element software ANSYS (2005).

The element types examined includ-

and the mesh refinement, were selected. A study to define these parameters was performed, and the results are presented.

The construction material was a steel S355 according to EN 10025 (2004), $\left(\sigma_{\mathrm{y}}=355 \mathrm{MPa}\right.$ and $\sigma_{\mathrm{u}}=510$ the design of uniplanar and multiplanar joints are presented in the CIDECT manual (Wardenier et al. 2008), the Eurocode 3 (2005), the Brazilian NBR 16239 (2013), Kurobane (1995), and Wardenier et al. (2010). The use of numerical simulation to evaluate the mechanical behavior of joints is adopted worldwide. The latest IIW (2012) and ISO 14346 (2013) recommendations for uniplanar circular hollow section $\mathrm{K}$ joints are primarily based on numerical data and checked with experimental results, see van der Vegte and Wardenier (2014).

Figure 2

Failure modes of KK joints.

eter, $t_{0}$ is its thickness;

- $\mathrm{g}_{i} \geq t_{1}+t_{2}$, where $\mathrm{g}_{\text {/ }}$ stands for the longitudinal gap and $t_{1}$ and $t_{2}$ are the brace thicknesses;

- $60^{\circ} \leq \varphi_{i} \leq 90^{\circ}$ (angle between planes in KK connections).

ed quadrilateral and triangular nonlinear SHELL181 elements for describing the tubes and quadrilateral and triangular linear SHELL63 elements for the plates at the chord extremities that defined the chord boundary conditions.

$\mathrm{MPa}$ ) commonly used in the European offshore industry. The stress-strain curve was obtained from van der Vegte et al. (1991). This material was implemented in ANSYS as the multilinear function depicted in Figure 3.

Figure 3

Stress-strain curve input to ANSYS. 
The boundary conditions are depicted in Figure 4. They were adopted with the objective that all members would be subject only to axial loads, with no extremity bending moments. The two left braces are under compression, and the two right braces are under tension. The chord has a simple support at the left end (i.e., on the same side as the compression braces) and a pinned support at the right end.

The chord is aligned with the $\mathrm{Z}$ axis,

Figure 4

Boundary conditions adopted for the KK joints.

Figure 5.

Chord pinned support:

(a) deformed shape demonstrating free rotation of the section and

(b) auxiliary plate and node constraints.

The forces acting on the braces in one plane of the multiplanar joint are symmetrical to the other plane. The braces are loaded by displacing the end nodes of the compression braces along their axes and toward the intersection. The normal force is then obtained from the support reactions.

Tension braces are only constrained, and no displacement is imposed on their nodes. The normal forces in tension should be equal (if the braces have the same angles) to the compression forces as a consequence of the joint equilibrium. However, the values differ, with the difference decreasing as the chord length increases and the bending rigidity is reduced. A numerical study was conducted to determine the chord length to be used in the simulations. The length of the chord was selected to minimize the difference between the normal forces in the compression and tension braces.

Simulations of one $\mathrm{KK}$ joint were performed using a variety of chord lengths. Chords with smaller lengths displayed greater bending rigidity, which induced boundary

Table 1

Study for determining the chord length. Comparison of support reactions in compression and tension braces. and the $\mathrm{Y}$ axis is the vertical upward direction. The simple support is simulated as a displacement constraint in the $\mathrm{Y}$ direction of all nodes at the left end. However, the pinned support required somewhat more attention. Constraining all nodes in the $\mathrm{Y}$ and $\mathrm{Z}$ directions would produce a fixed support because the cross section would not be allowed to rotate. To permit rotation but limit horizontal and vertical displacement, an auxiliary plate was placed at
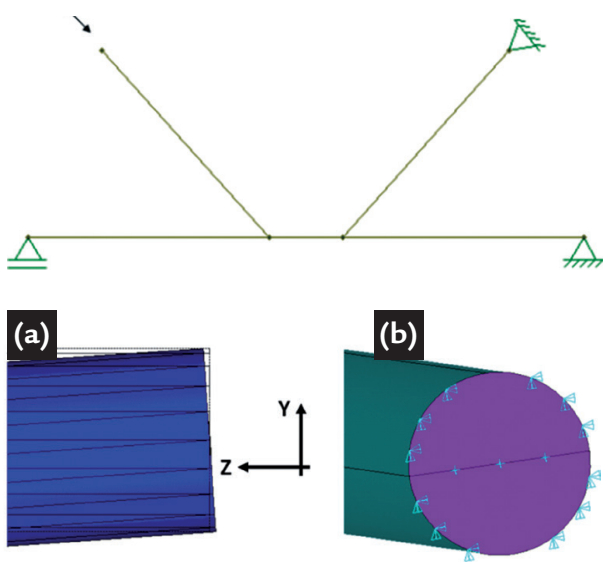

effects in the simulation solution. The boundary conditions were chosen to produce a simply supported chord having only normal forces at the chord ends. This assumption was intended to reproduce the stress state of pinned trusses, which are subject only to a normal force. However, this condition is only obtained when no eccentricities exist because eccentricities produce moments that are countered by vertical reactions in the chord supports.

Increased chord lengths tend to result in balanced brace normal forces. In the case of braces with the same angles, the normal forces should be of the same value. The results of this study are summarized in Table 1. The simulated joints had braces with equal angles and with eccentricity. The normal forces in the compression and the tension braces were compared for the loading instant when the diametric deformation (see Section 2.6.2) of the chord was $3 \%$. The brace members were $1.5 \mathrm{~m}$ long.

Lee and Wilmshurst (1995) recommend a chord length of 14 times the diameter the right end of the chord (Figure 5). This plate is thick enough that it undergoes only small strains. Using the plate, all nodes are constrained in the $Y$ direction, but displacement in the $\mathrm{Z}$ direction is prevented only for nodes at the center of the plate (Figure $5 \mathrm{~b})$, permitting the cross section to rotate but preventing displacement. Figure $5 \mathrm{a}$ is a diagram of the chord deformation in the vicinity of the pinned support, illustrating the rotation of the section about its center. for multiplanar KK joints. In this work, joints with chord diameters up to $141.3 \mathrm{~mm}$ were simulated, which when multiplied by 14 yields a length of $1.98 \mathrm{~m}$. When a joint with a chord length of $2 \mathrm{~m}$ and a diameter of $120 \mathrm{~mm}$ is simulated, a difference of $5.3 \%$ is obtained (Table 1). This value was considered excessive, and the chord length was adjusted to $3 \mathrm{~m}$, reducing the difference to $1.6 \%$.

The normal forces (which are support reactions) exhibit asymptotic behavior with respect to the chord length. The limiting average value was $119.5 \mathrm{kN}$, and a 3-meterlong chord produced a value of $117.7 \mathrm{kN}$, a difference of $1.5 \%$.

An analysis of the length of the brace members was also performed. Provided that no buckling occurs, braces should be long enough for the external loading to be uniformly distributed in the cross section. A brace length of $1.5 \mathrm{~m}$ resulted in joint resistance values only slightly less than those obtained using $0.75 \mathrm{~m}$ braces. Both lengths provided adequate results, and a length of $1.5 \mathrm{~m}$ was adopted for the brace members.

\begin{tabular}{c|c|c|c|c} 
Chord length $(\mathrm{m})$ & $\begin{array}{c}\text { Compression } \\
\text { brace }(\mathrm{kN})\end{array}$ & $\begin{array}{c}\text { Tension brace } \\
(\mathrm{kN})\end{array}$ & $\begin{array}{c}\text { Average value } \\
(\mathrm{kN})\end{array}$ & Difference (\%) \\
\hline 10 & 119.5 & 119.4 & 119.5 & 0.083 \\
\hline 4 & 119.0 & 118.3 & 118.7 & 0.59 \\
\hline 3 & 118.6 & 116.7 & 117.7 & 1.6 \\
\hline 2 & 116.8 & 110.8 & 113.8 & 5.3 \\
\hline
\end{tabular}




\subsection{Finite element mesh}

The simulation domain of the joint may be separated into two regions. The first is the region of intersection. This region contains the steepest stress gradient and must be refined using small mesh elements. The second region contains the ends of the members, where the stresses are more uniform and the mesh may be coarser. The mesh refinement parameters were defined

A uniform refinement of the central region using $5 \mathrm{~mm}$ elements was used during the optimization of the mesh development in the far field region. The far field region was discretized using three approaches:

1. Uniform refinement with $5 \mathrm{~mm}$ element size

2. Uniform refinement with $10 \mathrm{~mm}$ for the region of intersection (referred to as the central region) and the region of support (the far field region).

A study was performed to determine the mesh refinement necessary to provide an accurate simulation while minimizing the processing time. The central region was constructed using similarly sized elements. For the far field region, two approaches

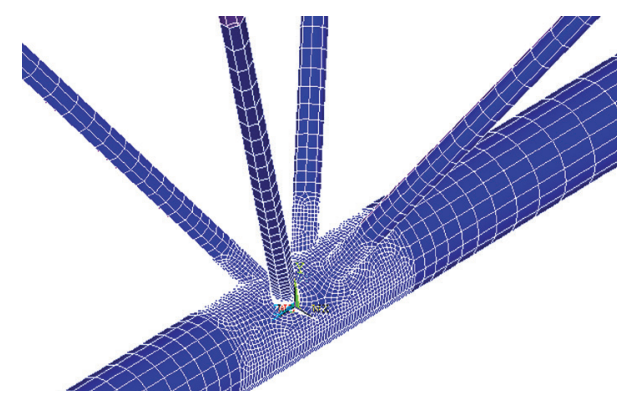

element size

3. Geometric progression of element size, dividing the end of each member into 30 elements with a size ratio of 1.1 .

The joint resistance and number of nodes results are provided in Table 2 . The joint resistance was determined from the brace loading when the diametric deformation of the chord (see Section 2.4) was were examined: uniformly discretizing the region using elements of approximately the same size and employing a geometric progression of element sizes. For the geometric progression approach, the chord was divided into 30 elements with a size ratio of 1.1. ANSYS provides both approaches for mesh generation. Figure 6 illustrates a mesh generated.
Figure 6

Mesh generation. Uniform

refinement in central region and geometric progression of element size in far field region.

$3 \%$. The results were equivalent, independent of the far field refinement approach, confirming that the three approaches are equally suitable. However, the mesh number of nodes were very different, with the geometric progression approach resulting in a greatly reduced amount of equations, which has a direct impact on the computational cost.

\begin{tabular}{c|c|c} 
Mesh refinement & Number of nodes & Joint resistance $(\mathrm{kN})$ \\
\hline $\begin{array}{c}\text { Central: } 5 \mathrm{~mm} \\
\text { Far field: } 5 \mathrm{~mm}\end{array}$ & 73679 & 117.35 \\
\hline $\begin{array}{c}\text { Central: } 5 \mathrm{~mm} \\
\text { Far field: } 10 \mathrm{~mm}\end{array}$ & 13709 & 117.32 \\
\hline $\begin{array}{c}\text { Central: } 5 \mathrm{~mm} \\
\text { Far field: geometric progression }\end{array}$ & 5379 & 117.32 \\
\hline
\end{tabular}

The next step was to define the mesh parameters in the central region. Table 3 provides the results of simulations in which the mesh size of the central region elements was varied and a progressive geometric approach was used in the far field region. Meshes with element sizes of $3 \mathrm{~mm}$ and 5 $\mathrm{mm}$ produced practically the same result,

\begin{tabular}{c|c} 
Size of elements in the central region $(\mathrm{mm})$ & Joint resistance $(\mathrm{kN})$ \\
\hline 10 & 120.5 \\
\hline 5 & 117.3 \\
\hline 3 & 116.2 \\
\hline
\end{tabular}

\subsection{Load step}

The numerical simulations applied the external forces and displacements in in- with a $40 \%$ reduction in the element size producing a difference in the results of less than $3.5 \%$. For this reason, a $5 \mathrm{~mm}$ element size was used for the central region. This refinement level, combined with the geometric progression approach in the far field regions, led to results very similar to those of the $3 \mathrm{~mm}$ mesh with a reduced cremental load steps. In these simulations, the loads were applied as displacements in
Table 2

Comparison of mesh refinement approaches in far field region.

computational effort.

Some researchers (for example, Lee and Wilmshurst 1996) have recommended that the elements in the central region have a size equal to the chord thickness, which in the simulations presented herein is $5 \mathrm{~mm}$. This confirms the choice of this refinement level.

Table 3

Comparison of mesh

refinement in central region.

the compression braces. The final displacement and the number of steps were defined 
at the beginning of the simulation. The size of the load step is important for the joint resistance computation because the joint may fail between steps. For example, in the search for the load producing a diametric deformation (see Section 2.4) of 3\%, the applied load may fall anywhere within a selected level of precision, which in this case would be between $2.95 \%$ and $3.05 \%$.

\subsection{Failure Criteria}

The joint resistance was defined as the brace axial force at which one of the following failure criteria was reached:

- A peak in the load-displacement curve;

- A diametric deformation in the chord of $3 \%$;

- Brace failure in tension, compression, or buckling.

These criteria are internationally recognized, and the work of van der Vegte and Makino (2004) may be cited as an example

where $\mu_{1}$ and $\mu_{2}$ are the horizontal displacement of nodes B and B' indicated in Figure $7 \mathrm{a}$ or the vertical displacement of nodes $\mathrm{A}$ and A', also indicated in Figure 7a. Figure 8 illustrates the diametric deformation in the vertical and horizontal directions. The diametric deformation was limited to $3 \%$.

It is important to observe that the diametric deformation in the vertical direction is similar to Lu's deformation

The default number of steps was set at 50 . When the simulation results fell outside the accepted range, repeated simulations were performed using more steps until the results were in range. The total displacement must be chosen carefully, or even 50 steps might not be sufficient.

Another important issue related to the load step is the solution convergence

of work using similar criteria. A limited diametric chord deformation criterion is proposed as an extension of Lu's deformation criterion (Lu et al. 1994).

Because of plasticity effects, there is a point in the loading at which the support reactions do not increase with further increases in the imposed displacement. This peak in the load-displacement curve indicates the maximum joint resistance.

An important criterion known as Lu's deformation (Lu et al. 1994) defines

$$
\epsilon_{\text {diametral }}=\frac{\mu_{2}-\mu_{1}}{D}
$$

when applied to $\mathrm{K}$ joints, resulting in equivalent results. This equivalence was confirmed by the authors in a numerical study of 31 uniplanar $\mathrm{K}$ joints, in which the maximum difference in the joint resistance obtained from the two deformation measures was less than $3 \%$.

This modified criterion was necessary for the assessment of multiplanar $\mathrm{KK}$ joints for which no equivalent cri-

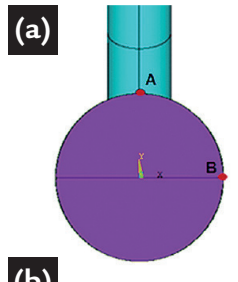

(b)

Figure 7

a) Lu's deformation for uniplanar K joints and its extension to multiplanar KK joints;

b) Diametric deformation of the chord: horizontal deformation (failure mode 1) and vertical deformation (failure mode 2 ).

The failure mode is directly influenced by the diametric deformation behavior. Failure mode 1 is characterized by more prominent deformation in the horizontal direction, whereas failure mode

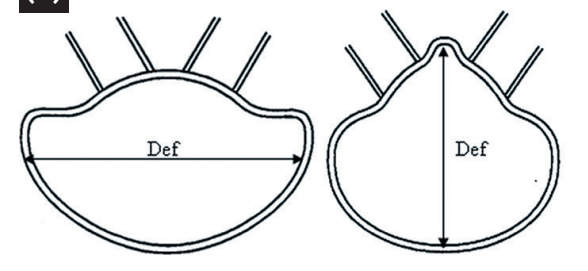

2 is the result of greater deformation in the vertical direction. This observation is used in Section 4 to define an objective criterion for identifying the failure mode of KK joints. process within ANSYS. The solution is determined at each load step by solving nonlinear equations using the NewtonRaphson method. The greater the load step, the greater the difficulty in obtaining convergence with this method, and in some cases, the solutions do not converge. For better convergence, the line search option in ANSYS was set to be true.

the joint resistance as the force at which the diametric deformation of the chord reaches $3 \%$ of the chord diameter. Lu's deformation is computed as the relative vertical displacement of the points indicated as A and B in Figure 7a. Herein, we have proposed to extend Lu's criterion to multiplanar joints. The proposed criterion describes the ovalization of the chord cross section. The criterion is given by the relative displacement of diametrically opposed nodes divided by the chord diameter:

terion was provided in literature. This criterion, as an extension of Lu's, is also suitable for uniplanar $\mathrm{K}$ joints, what would permit both $\mathrm{K}$ and $\mathrm{KK}$ joints to be compared under the same criteria. This is an interesting aspect since most standard design specifications define the $\mathrm{KK}$ joint resistance by multiplying the resistance of the corresponding $\mathrm{K}$ joint by a correction factor.

\section{Validation of the Numerical Model}

The numerical model was validated by comparing the output of the model to the results of Lee and Wilmshurst (1996),
Brace failure may occur before the joint violates any of the previous criteria, in which case the joint resistance is limited by the brace. In this work, the simulated joints were designed to exclude brace failure. 
who validated their simulations against laboratory tests. That study is summarized in Table 4, in which the symbols used are defined in Figure 1. The joints have the following common data: the in-plane angle between braces and the chord $\theta_{i}=60^{\circ}$, the same for both braces; angle between the two planes $\varphi=60^{\circ}$; chord diameter $D=120 \mathrm{~mm}$; chord thickness $\mathrm{t}_{0}=5 \mathrm{~mm}$; braces thickness $\mathrm{t}_{\mathrm{i}}=4 \mathrm{~mm}$; eccentricity of the two planes $e_{t}=0$. They vary on: brace diameter $d_{;}$; longitudinal gap $\mathrm{g}_{\mathrm{j}}$; transversal gap $\mathrm{g}_{\mathrm{t}} ; \beta$ parameter, which relates the braces diameter to the chord's. These values are indicated in Table 4, which also presents: $F_{\text {authors }}$, the joint resistance computed in this work; $F_{\text {ref }}$, the values of Lee and Wilmshurst (1996); the difference between them; and the joint resistance calculated using the Eurocode 3 (2005). It also brings the failure mode identified by Lee and Wilmshurst (1996) and identified following the criterion presented later in Section 4.

Table 4 - Data from simulated joints.

\begin{tabular}{|c|c|c|c|c|c|c|c|c|c|c|}
\hline \multirow{2}{*}{ Joint ID } & \multirow{2}{*}{$\mathrm{d}_{\mathrm{i}}(\mathrm{mm})$} & \multirow{2}{*}{$\mathrm{g}_{1}(\mathrm{~mm})$} & \multirow{2}{*}{$\mathrm{g}_{\mathrm{t}}(\mathrm{mm})$} & \multirow{2}{*}{$\beta=d_{i} / d_{0}$} & \multicolumn{2}{|c|}{ This work } & \multicolumn{2}{|c|}{$\begin{array}{l}\text { Lee and Wilmshurst } \\
\qquad(1996)\end{array}$} & \multirow{2}{*}{$\begin{array}{c}\text { Difference } \\
F_{\text {ref }} / F_{\text {authors }}-1\end{array}$} & \multirow{2}{*}{$\begin{array}{c}\text { Eurocode } 3 \\
(2005)\end{array}$} \\
\hline & & & & & $F_{\text {authors }}(\mathrm{kN})$ & Failure Mode & $F_{r e f}(\mathrm{kN})$ & Failure Mode & & \\
\hline SKK-01 & 28.8 & 18 & 33.4 & 0.24 & 105.0 & 1 & 108.8 & 2 & $3.6 \%$ & 76.3 \\
\hline SKK-02 & 28.8 & 28 & 33.4 & 0.24 & 101.3 & 1 & 103.6 & 2 & $2.3 \%$ & 70.1 \\
\hline SKK-03 & 28.8 & 38 & 33.4 & 0.24 & 101.1 & 1 & 99.9 & 2 & $-1.2 \%$ & 66.8 \\
\hline SKK-04 & 28.8 & 48 & 33.4 & 0.24 & 99.5 & 1 & 99.4 & 2 & $-0.1 \%$ & 65.3 \\
\hline SKK-05 & 28.8 & 58 & 33.4 & 0.24 & 99.1 & 1 & 99.4 & 2 & $0.3 \%$ & 64.8 \\
\hline SKK-06 & 28.8 & 68 & 33.4 & 0.24 & 99.6 & 1 & 99.1 & 2 & $-0.5 \%$ & 64.5 \\
\hline SKK-07 & 38.4 & 18 & 23.6 & 0.32 & 125.3 & 1 & 137.9 & 1 & $10.1 \%$ & 90.8 \\
\hline SKK-08 & 38.4 & 28 & 23.6 & 0.32 & 120.8 & 1 & 126.3 & 1 & $4.5 \%$ & 83.6 \\
\hline SKK-09 & 38.4 & 38 & 23.6 & 0.32 & 118.3 & 1 & 120.1 & 1 & $1.5 \%$ & 79.6 \\
\hline SKK-10 & 38.4 & 48 & 23.6 & 0.32 & 117.7 & 1 & 118.5 & 1 & $0.7 \%$ & 77.9 \\
\hline SKK-11 & 38.4 & 58 & 23.6 & 0.32 & 116.0 & 1 & 118.0 & 1 & $1.7 \%$ & 77.2 \\
\hline SKK -12 & 48.0 & 18 & 13.4 & 0.4 & 140.2 & 1 & 159.0 & 1 & $13.4 \%$ & 105.4 \\
\hline SKK-13 & 48.0 & 28 & 13.4 & 0.4 & 135.4 & 1 & 143.5 & 1 & $6.0 \%$ & 97.0 \\
\hline SKK-14 & 48.0 & 38 & 13.4 & 0.4 & 131.8 & 1 & 135.4 & 1 & $2.7 \%$ & 92.4 \\
\hline SKK-15 & 48.0 & 48 & 13.4 & 0.4 & 128.8 & 1 & 132.9 & 1 & $3.2 \%$ & 90.4 \\
\hline
\end{tabular}

The results correlated well, except in the case of joints with smaller longitudinal gaps between the braces, i.e., joints SKK-07 and SKK-12. The deviation in the results may occur because the numerical model of Lee and Wilmshurst (1996) included a simulated weld that was omitted in the present work. The presence of the weld results in a smaller net distance between the braces, and the relative reduction in the distance is greater for joints with small longitudinal gaps.

The absence of a weld in the model would also affect joints with small values of the parameter $\beta$ (the brace diameter divided by the chord diameter, $\left.\beta=d_{i} / D\right)$. In this case, the lack of a weld may lead to excessive local strains in the chord in the region where the braces connect to it. The presence of a weld would better distribute the compression and tension forces, producing smaller local strains and improving the quality of the simulation.

\section{An objective criterion for identifying KK failure mode}

Literature identifies two failure modes occurring when a KK joint is symmetrically loaded (Makino et al. 1984). Joints with a small transversal gap usually fail in mode 1 (Figure 2a), in which the two diagonal braces act in unison without wall deformation in the transversal gap region.
Other joints fail in mode 2 (Figure 2b), where excessive deformation occurs near the transversal gap. These definitions are widely employed, although they are based on visual observation.

Therefore, it is important to define an objective criterion for identifying the failure mode of $\mathrm{KK}$ joints as mode 1 or mode 2 . It is proposed to define the failure mode based on the maximum diametric deformation, instead of a visual inspection.

Failure mode 1 is characterized by the excessive diametric deformation of the chord cross section in the horizontal 
direction. If the diametric deformation reached $3 \%$ in the horizontal direction (Figure 8 left), the failure is considered a mode 1 failure.

Failure mode 2 is characterized by more pronounced deformation in the region between planes, producing an edge in the chord wall. If the diametric deformation reached $3 \%$ in the vertical direction (Figure 8 right), the failure mode is considered to be failure mode 2 .

However, there are joints that present substantial diametric deformation in both directions. These joints do not provide a visually well-defined failure mode, and ex-

Figure 8

Excessive diametric deformations: a) in the horizontal direction (failure mode 1); b) in the vertical direction (failure mode 2). hibit features of both modes 1 and 2 . These deficiencies highlight the need for an objective criterion. Using the proposed criterion described, the failure mode is determined based on whether it is the horizontal or vertical diametric deformation that first reaches $3 \%$.

Lee and Wilmshurst (1996) found the value of $\xi_{\tau}=g_{t} / d_{0}=0.25$ (see Figure 1 for geometric data) as the demarcation value between failure modes 1 and 2 and Paul et al (1994) present graphics where the failure mode changes close to the value of $\zeta \mathrm{t} \cong 0.18$. The differences between these two studies may be credited to the difficulty in

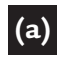

.
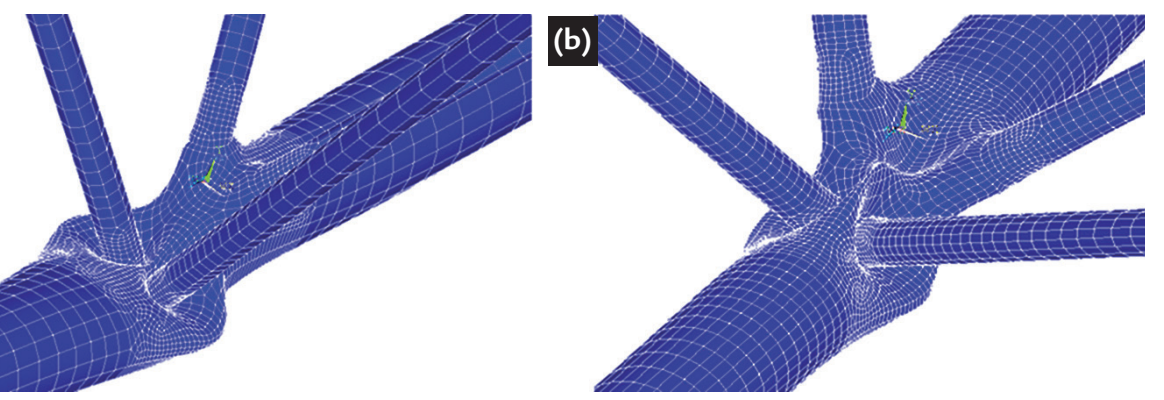

determining the transition of failure modes, when the connection exhibits features of both modes 1 and 2 . This motivates the definition of a clear objective criterion, as proposed herein.

In Table 4, one can observe the failure mode identified by Lee and Wilmshurst (1996), which differs from our studies. It is caused by the adoption of different criteria. While Lee and Wilmshurst (1996) adopts the visual identification, employed herein was the objective-proposed criterion. Table 5 brings other simulations performed to this work, where the proposed criterion is also adopted.

\begin{tabular}{|c|c|c|c|c|c|c|c|c|}
\hline & Joint ID & $\mathrm{d}_{\mathrm{i}}(\mathrm{mm})$ & $\mathrm{g}_{\mathrm{l}}(\mathrm{mm})$ & $\phi_{\mathrm{t}}(\mathrm{mm})$ & $\mathrm{g}_{\mathrm{t}}(\mathrm{mm})$ & $\beta$ & $\begin{array}{l}\mathrm{F}_{\text {authors }} \\
(\mathrm{kN})\end{array}$ & $\begin{array}{c}\text { Failure } \\
\text { mode }\end{array}$ \\
\hline & KK_01 & 38 & 35 & 90 & 49.5 & 0.33 & 98.4 & 2 \\
\hline & KK_02 & 38 & 55 & 90 & 49.5 & 0.33 & 97.6 & 2 \\
\hline & KK_03 & 38 & 35 & 60 & 21.2 & 0.33 & 99.1 & 1 \\
\hline & KK_04 & 38 & 55 & 60 & 21.2 & 0.33 & 96.4 & 1 \\
\hline & KK_05 & 38 & 35 & 75 & 35.5 & 0.33 & 103.2 & 1 \\
\hline & KK_06 & 38 & 55 & 75 & 35.5 & 0.33 & 102.1 & 1 \\
\hline & KK_07 & 44.5 & 35 & 90 & 43.1 & 0.39 & 121.5 & 2 \\
\hline & KK_08 & 44.5 & 55 & 90 & 43.1 & 0.39 & 120.2 & 2 \\
\hline & KK_09 & 44.5 & 35 & 60 & 14.3 & 0.39 & 105.7 & 1 \\
\hline & KK_10 & 44.5 & 55 & 60 & 14.3 & 0.39 & 101.9 & 1 \\
\hline & KK_11 & 44.5 & 35 & 75 & 28.8 & 0.39 & 117.6 & 1 \\
\hline & KK_12 & 44.5 & 55 & 75 & 28.8 & 0.39 & 115.1 & 1 \\
\hline & KK_13 & 46 & 35 & 90 & 41.3 & 0.40 & 127.4 & 2 \\
\hline & KK_14 & 48 & 35 & 90 & 38.7 & 0.42 & 137.6 & 1 \\
\hline & KK_15 & 50.8 & 35 & 90 & 36.6 & 0.44 & 146.8 & 1 \\
\hline & KK_16 & 50.8 & 55 & 90 & 36.6 & 0.44 & 143.9 & 1 \\
\hline & KK_17 & 50.8 & 35 & 60 & 7.4 & 0.44 & 112.9 & 1 \\
\hline & KK_18 & 50.8 & 55 & 60 & 7.4 & 0.44 & 107.9 & 1 \\
\hline Table 5 & KK_19 & 50.8 & 35 & 75 & 22.0 & 0.44 & 129.9 & 1 \\
\hline Details of series $2\left(\theta_{i}=60^{\circ} ; \gamma=13\right.$; & KK_20 & 50.8 & 55 & 75 & 22.0 & 0.44 & 124.3 & 1 \\
\hline
\end{tabular}




\section{Conclusions}

A methodology for numerical analyses of tubular KK joints is presented. The definition of the numerical model required auxiliary studies; for instance, to define the length of the chord and the necessary mesh refinement to produce sufficiently accurate results with minimal computational cost. A modified failure criterion, which is an extension of Lu's deformation, is proposed to be applied in $\mathrm{KK}$ joints. The model was validated by comparing the results to previously published results. The model does not account for the weld joining the braces to the chord, which prevents it from simulating joints with small gaps or small values of $\beta=d / D$.

This work also proposes an objective criterion to identify the failure mode (1 or 2 ) of the KK joints based on the diametric deformation of the chord, instead of the visual criterion often employed. Including a weld in the model is also possible.

\section{Acknowledgements}

The authors thank CAPES and V\&M do Brasil Company for their financial support of this research.

\section{References}

ANSYS, Swanson Analysis Systems. Inc. P.O. Box 65. Johnson Road, Houston, PA, 15342-0065, version 10.0, Basic analysis procedures, Second edition, 2005.

EN 10025. "Hot rolled products of structural steels". 2004.

Eurocode 3. "Design of Steel Structures": DIN EN 1993 -1-8, Part 1.-81: Design of Joints. 2005.

FORTI, N.C.S, REQUENA, J.A.V, FORTI, T.L.D, Parametric study of tubular KK multiplanar steel connections. Journal of Constructional Steel Research, v. 114, p. 188-195, 2015. doi: 10.1016/j.jcsr.2015.07.010

IIW: "Static design procedure for welded hollow section joints - Recommendations", 3rd ed., IIW Doc. XV-1402-12, International Institute of Welding, Paris, France, 2012.

ISO 14346: "Static Design Procedure for Welded Hollow-Section Joints - Recommendations”, International Standards Organisation, Geneva, Switzerland; 2013.

KUROBANE, Y. Ultimate behavior and design of multiplanar tubular joint. In: Proceedings of the Workshop on Requalification of Tubular Steel Joint in Offshore Structure. Houston, TX, 1995.

LEE, M.M.K., WILMSHURST, S.R. Numerical modeling of CHS joints with multiplanar double-K configuration. J Constr Steel Res, n. 32, p.281-301, 1995.

LEE, M.M.K., WILMSHURST, S.R. Parametric study of strength of tubular multiplanar KK-joints. J Struct Eng, n. 122, p.893-904, 1996.

LEE, M.M.K., WILMSHURST, S.R. Srength of Multiplanar tubular KK-joints under antisymmetrical axial loading. J Struct Eng, n.123, p.755-64, 1997.

LU, L.H., WINKEL, G.D.D., YU, Y., WARDENIER, J. Deformation limit for the ultimate strength of hollow section joints. In: Proceedings of the 6th International Symposium on Tubular Structure. Rotterdam: Balkema, 1994. p. 341-347.

MAKINO, Y., KUROBANE, Y., OCHI, K. ULTIMATE capacity of tubular double K-joints. In: Proceedings of the 2nd International Institute of Welding Conference on Welding of Tubular Structure. Tarrytown, NY: Pergamon Press, 1984. p. 458.

MAKINO, Y., KUROBANE, Y., PAUL, J.C. Ultimate behaviour of diaphragm-stiffened tubular KK-joints. In: Proceedings of the International Symposium on Tubular Structure. 1993. p. 472.

MOUTY, J., RONDAL, J. Etude du comportement sous charge statique des assemblages soudés de profiles creux circulaires dans les poutres de section triangulaires et quadrangulaires. Liège, Belgium: University of Liège, 1990.

NBR 16239. "Design of steel and composite structures for buildings using hollow sections”, Associação Brasileira de Normas Técnicas ABNT; São Paulo, Brazil; 2013.

PAUL, J.C., MAKINO, Y., KUROBANE, Y. Ultimate behaviour of multiplanar double K-joints. In: Proceedings of the International Offshore and Polar Engineering Conference. 1992. p. 383.

PAUL, J. C., MAKIN, Y., KUROBANE, Y. Ultimate resistance of unstiffened multiplanar tubular TT- and KK- joints. Journal of Structural Engineering, American Society of Civil Engineers, v.120, n.10, p. 2853-2870, 1994.

VAN DER VEGTE, G.J., VAN DER KONING, C. H. M., PUTHLI, R. S., WARDENIER, J. Numerical simulation of experiments on multiplanar tubular steel X-joints. 
Int. J. of Offshore and Polar Engrg; 1991. 1, p. 200-207.

VAN DER VEGTE, G.J., MAKINO, Y. The influence of boundary conditions on the chord load effect for CHS gap K-joints. In: CONNECTIONS IN STEEL STRUCTURES 5. June 3-4. Amsterdam: 2004.

VAN DER VEGTE, G.J., WARDENIER, J. Evaluation of the recent IIW (2012) and ISO (2013) strength equations for axially loaded CHS K gap joints. Steel Construction, n.7, p. 97-106, 2014. doi: 10.1002/stco.201410022.

WARDENIER, J., KUROBANE, Y., PACKER, J.A., VAN DER VEGTE, G.J., ZHAO, X.L. Design guide for circular hollow section (CHS) joints under predominantly static loading (1). CIDECT, Verlag, and TÜV Rheinland, 2008.

WARDENIER, J., PACKER, J.A., ZHAO, X.L., VAN DER VEGTE, G.J. Hollow section in structural applications. CIDECT, 2010.

Received: 29 October 2014 - Accepted: 3 January 2016. 